\title{
Field Evaluation of Nitrogen Fixing Endophytic Bacterium Gluconacetobacter diazotrophicus NFGM5 on Growth and Yield of Maize
}

\author{
Hema C. Rao* and V.P. Savalgi \\ Department of Agricultural Microbiology, University of Agricultural Sciences, Dharwad- \\ 580005, Karnataka, India \\ *Corresponding author
}

\section{Keywords}

Gluconacetobacter diazotrophicus, Growth parameters, Per cent Nitrogen, Nitrogen uptake, Yield parameters and Maize

Article Info

Accepted:

12 December 2018 Available Online: 10 January 2019

\section{A B S T R A C T}

A field experiment was conducted with efficient isolates of endophytic nitrogen fixing bacteria i.e., Gluconacetobacter diazotrophicus NFGS25 and NFGM5 which were isolated from the roots of sugarcane and maize, based on the results of pot culture studies on maize. NFGS25 and NFGM5 were confirmed by the molecular characterization using 16S rDNA method. At 30 DAS(days after sowing), the growth parameters such as plant height (52.17 $\mathrm{cm})$, stem girth $(3.53 \mathrm{~cm})$, chlorophyll content $(32.5)$, root length $(60 \mathrm{~cm})$, dry matter production of shoot ( $3.5 \mathrm{~g}$ per plant) and root $(0.57 \mathrm{~g}$ per plant) of maize were maximum in the treatment inoculated with NFGM5 at $75 \%$ RDN level. The per cent shoot nitrogen content was maximum in the treatment inoculated with, NFGM5 and NFGS25 at $75 \%$ RDN $(0.37 \%)$. At $100 \%$ RDN, NFGM5 recorded higher shoot nitrogen of $0.27 \%$ as compared to NFGS25 $(0.23 \%)$ at 30 DAS. The nitrogen uptake was significantly higher in the treatment NFGM5 at $75 \%$ RDN $\left(8.65 \mathrm{~g} \mathrm{plant}^{-1}\right)$ followed by NFGS25 $\left(7.73 \mathrm{~g} \mathrm{plant}{ }^{-1}\right)$. The population of $G$. diazotrophicus was maximum in the treatment inoculated with NFGM5 at $75 \%$ RDN $\left(9.8 \times 10^{4} \mathrm{CFU} \mathrm{g}^{-1}\right)$ followed by NFGS25 $\left(3.5 \times 10^{4} \mathrm{CFU} \mathrm{g}^{-1}\right)$ at 60 DAS. The yield parameters like number of cobs per plant (2.07), cob weight per plant $(295.93 \mathrm{~g})$, grain yield per plant $(250.03 \mathrm{~g})$, grain yield $\left(183.33 \mathrm{q} \mathrm{ha}^{-1}\right)$ and test weight $(40.17 \mathrm{~g})$ were significantly highest in the treatment NFGM5 at $75 \%$ RDN followed by NFGS25 at $75 \%$ RDN. It is evident that, Gluconacetobacter diazotrophicus isolates inoculated with graded level of recommended dose of nitrogen promotes plant growth and grain yield under field condition.

\section{Introduction}

The endophytic nitrogen fixation concept has been recently gaining momentum. The biologically fixed nitrogen can supplement the nitrogen requirement of the crops in case of $\mathrm{N}$ deficit soils. Another important trait beneficial to the plant health is the production of growth hormones. G. diazotrophicus has the ability to produce both auxins and gibberellins in significant quantities (Bastian et al., 1998; Dobereiner, 1992; Baldani and Baldani, 2005; Dong et al., 1995).

Gluconacetobacter diazotrophicus is an endophytic bacterium first isolated from the 
sugarcane growing regions of Brazil (Cavalcante and Dobereiner, 1988). It was widely studied and used as a model system to assess the bacterial endophyte- plant interactions. Gluconacetobacter diazotrophicus is in the phylum Proteobacteria, the class Alpha Proteobacteria, the order Rhodospirillales, the family Acetobacteraceae, and genus Gluconacetobacter (Kersters et al., 2006). After its first discovery, it was reported from variety of crops viz, coffee (Jimenez-Salgado et al., 1997), ragi (Loganathan et al., 1999), pineapple (Hernandez et al., 2000) and a latest report states Gluconacetobacter $s p$. as a natural colonizer of the wild rice (Porteresia coarctata Tateoka, formerly Oryza coarctata Roxb.) and a salt tolerant Pokali rice variety (Loganathan and Nair, 2003). These reports clearly indicated the wide occurrence of $G$. diazotrophicus in different plants than initially expected.

Association between G. diazotrophicus and plants is not species specific, like rhizobia, which associate only with specific legume plants. It has been found in a number of unrelated plant species (Cocking et al., 2006).

Maize provides nutrients for humans and animals and serves as a basic raw material for the production of starch, oil, protein, alcoholic beverages, food sweeteners and more recently, as a biofuel crop in India. Maize occupies an important place as food $(25 \%)$ and as animal feed $(12 \%)$. In India, most of the research work using Gluconacetobacter diazotrophicus is focused on sugarcane crop. Therefore, in this study maize was chosen as a test crop as it is also an exhaustive crop which requires high amount of nitrogen.

\section{Materials and Methods}

Based on the pot studies, two multifunctional efficient isolates (NFGS25 and NFGM5) were selected for the field experiment along with the reference strains G.diazotrophocus (MTCC no.1224) and Azospirillum ACD 15. A field experiment was conducted in Main Agricultural Research Station, University of Agricultural Sciences, Dharwad, Karnataka state, India during 2016 to study the influence of selected efficient G.diazotrophocus isolates on the growth and yield of maize at different levels of RDN.

The hybrid of maize used for the study was Pioneer (P-3401). Fertilizers (150: 75:37.5 $\mathrm{N}: \mathrm{P}_{2} \mathrm{O}_{5}: \mathrm{K}_{2} \mathrm{O} \mathrm{kg} \mathrm{ha}{ }^{-1}$ ) and farm yard manure (FYM - $10 \mathrm{t} \mathrm{ha}^{-1}$ ) was added as per the package of practices. The statistical design was two factorial RCBD (Randomized Complete Block Design). The treatments were imposed with 4 cultures at 3 levels of RDN (50\%, $75 \%$ and $100 \%)$.

The $72 \mathrm{~h}$ old culture of $G$. diazotrophicus inoculum was prepared in LGI broth. The culture broth was then mixed at the rate of $30 \mathrm{ml}$ per $100 \mathrm{~g}$ of lignite powder with one per cent Carboxy Methyl Cellulose (CMC) and one per cent gum Arabica. Seed bacterization was done according to Eskin et al., 2014 for Maize hybrid P-3401. Biocoated seeds were hand dibbed at the rate of two seeds per hill to about four centimeters depth with a spacing of $60 \times 20 \mathrm{~cm}$ and covered with soil. Fertilizer application was done at the time of sowing.

The plant growth parameters like plant height, girth of the stem, leaf chlorophyll content (SPAD - Soil and Plant Analysis Development), root length, shoot and root dry matter content were recorded at 30,60 DAS and at harvest. The microbial analysis (population dynamics) and nitrogen content of root and shoot (Microkjeldhal's method as outlined by Jackson, 1973) was analysed at 30, 60 DAS and at harvest. The crop in the net plot area of each plot was harvested at 120 DAS. After complete drying of the cobs, the 
husk was removed and the grains were separated. The grains were cleaned and weight of the grains per net plot was recorded. The yield parameters like number of cobs per plant, cob weight, grain weight, test weight, yield per plant and yield per hectare were recorded.

\section{Results and Discussion}

The results of the field experiment revealed that the growth parameters viz., plant height, girth of the stem, chlorophyll content and dry matter production were maximum in the treatment inoculated with NFGM5 at $75 \%$ RDN which was on par with $100 \%$ RDN treatment with NFGM5 at 30, 60 DAS and at harvest (Fig. 1, 2, 3, 4, and 5). The UIC (un inoculated control) at $100 \%$ RDN level was found to be on par with the treatments inoculated with reference strains at $75 \% \mathrm{RDN}$ level, efficient isolate NFGM5 at $75 \%$ RDN level and reference strains at $100 \% \mathrm{RDN}$ level. The increase in plant height may be due to the availability of abundant nitrogen during the plant growth through biological nitrogen fixation. The present study has reaffirmed that inoculated plant produce higher biomass than the uninoculated control.

The length of shoot and the root of rice seedlings increased due to inoculation with $G$. diazotrophicus according to Anitha and Thangaraju (2010). They also reported that it is because of IAA production $\left(4.74 \mu \mathrm{g} \mathrm{ml}^{-1}\right)$, nitrogenase activity and $\mathrm{P}$ solubilization. The results of this study are in conformity with the results obtained by Eskin et al., (2014). There was better growth of maize crop with the inoculation of $G$. diazotrophicus (Tian et al., 2009).

In the present investigation, significant increase in the grain yield was obtained as a result of inoculation of $G$. diazotrophicus isolates at different nitrogen levels. The results revealed that the yield attributing characteristics viz., number of cobs, cob weight, test weight, grain weight per plot and grain weight per ha were maximum in the treatment inoculated with NFGM5 at $75 \%$ RDN level which was significantly higher than the treatments inoculated with efficient isolate NFGM5 at $100 \%$ RDN level and NFGS25 at $75 \%$ RDN (Fig. 9, 10 and 11, Plate No.2).

On a practical basis, the grain yield is certainly the most important factor for determining the effectiveness of any agricultural treatment. In the present study highest grain yield $\left(183.33 \mathrm{q} \mathrm{ha}^{-1}\right)$ was observed in the treatment inoculated with NFGM5 at $75 \%$ RDN level, followed by NFGS25 which was more than the treatment inoculated with reference strains at $75 \% \mathrm{RDN}$ level and UIC $100 \%$ RDN.

The precise mechanism of increased grain yield due to inoculation is unknown. Generally yield parameter depends on plant growth characteristics. However, in the present study, inoculated microorganisms possessed the ability of nitrogen fixation and production of growth promoting substances. This growth promotional activity helps for vigorous plant growth characteristics which in turns correlate the yield attributes.

The results of the yield attributes confirmed with earlier findings of Luna et al., (2012) who showed increased grain yield of tomato as influenced by $G$. diazotrophicus under field condition with graded level of RDN. Dent and Cocking (2017) reported that inoculation of $G$. diazotrophicus improved the yield of maize and wheat which was due to possible combination of symbiotic nitrogen fixation, enhanced rate of photosynthesis and the presence of additional plant growth factors. In the present investigation, plants inoculated with Azospirillum as well as efficient isolates 
of $G$. diazotrophicus with graded levels of RDN showed increased ' $N$ ' concentration (\% N), (Fig. 6 and 7). The possible mechanisms for higher ' $N$ ' accumulation may be the transfer of atmospheric nitrogen to the plant through biological nitrogen fixation and improved nitrogen uptake in the inoculated plants (Anitha and Thangaraju, 2010).

In the present study, the available nitrogen increased significantly due to inoculation at different levels of RDN as compared to UIC. The maximum available nitrogen content was observed in the treatment inoculated with NFGM5 at $75 \%$ RDN level which was on par with the treatment inoculated with reference strains at $75 \%$ RDN level. The increase in the available nitrogen may be due to the activity of inoculated microbial group. They possess the ability to fix atmospheric nitrogen. However, the soil available nitrogen did not change at greater extent as compared to initial available nitrogen.

In the present study, the significant increase in population of inoculated group was observed. The population of $G$. diazotrophicus was maximum in the treatment inoculated with NFGM5 at $75 \%$ RDN level followed by the treatment inoculated with efficient isolate NFGS25at $75 \%$ RDN level. They were on par with reference strain 1 at $75 \%$ RDN level. Similarly, the population of Azospirillum was maximum in the treatment inoculated with ref. strain 2 at $75 \%$ RDN level which was on par with Azospirillum ACD 15 at $50 \%$ RDN level (Fig. 8).

In the present study, it also was noticed that the population of inoculated group showed relatively low numbers at harvest, but their numbers increased gradually up to 60 DAS. However, at the maturity stage, the population was in general slightly higher than at 30 DAS. The reason for decreased population may be due to: (1) a rapid depletion of available $\mathrm{N}$ in the soil (2) increased supply of plant photosynthates to roots (3) increased transport of atmospheric nitrogen to the roots through the aerenchyma at heading and (4) increased availability of carbon compounds due to partial degradation of plant roots at this stage of growth. The results reported here are in accordance with earlier reports by Anitha and Thangaraju (2010) who reported highest population of $G$. diazotrophicus and Azospirillum at $60 \mathrm{DAS}$ in maize.

The higher shoot length and stem girth were observed in the treatment inoculated with NFGM5 at $75 \%$ RDN level which was on par with the other treatments inoculated with efficient isolate NFGM5 at $100 \%$ RDN level followed by another efficient isolate NFGS25 at $75 \%$ RDN level. A similar result has been reported earlier by Anitha and Thangaraju (2010). The production of growth hormones may be responsible for vigorous shoot growth of the seedlings. Further, nitrogen fixation could help the shoot growth and in turn yield.

Overall results (growth, yield and biological properties of the soil) of the present investigation revealed that inoculation of efficient isolates of G. diazotrophicus at $75 \%$ RDN level were on par with the treatment inoculated with ref. strain 2 (Azospirllum $\mathrm{ACD} 15)$ at $75 \%$ RDN level. They were found to be superior as compared to all other treatments. The UIC at $100 \%$ RDN level was found to be on par with the efficient isolate NFGM5 at $75 \%$ RDN level. It clearly indicated that inoculation of efficient isolates at $75 \%$ RDN level can save $25 \%$ RDN. Even inoculation of efficient isolate NFGM5 at 100 $\%$ RDN also was superior as compared to UIC at $100 \%$ RDN. The G. diazotrophicus is versatile in nature and exhibited good growth under different nitrogen levels. The performance of efficient isolates of $G$. diazotrophicus in pot and field condition was similar in terms of functional characteristics. 
Fig.1 Plant height of maize as influenced by inoculation with efficient native isolates of Gluconacetobacter sp. at various nitrogen levels nitrogen levels in the field experiment

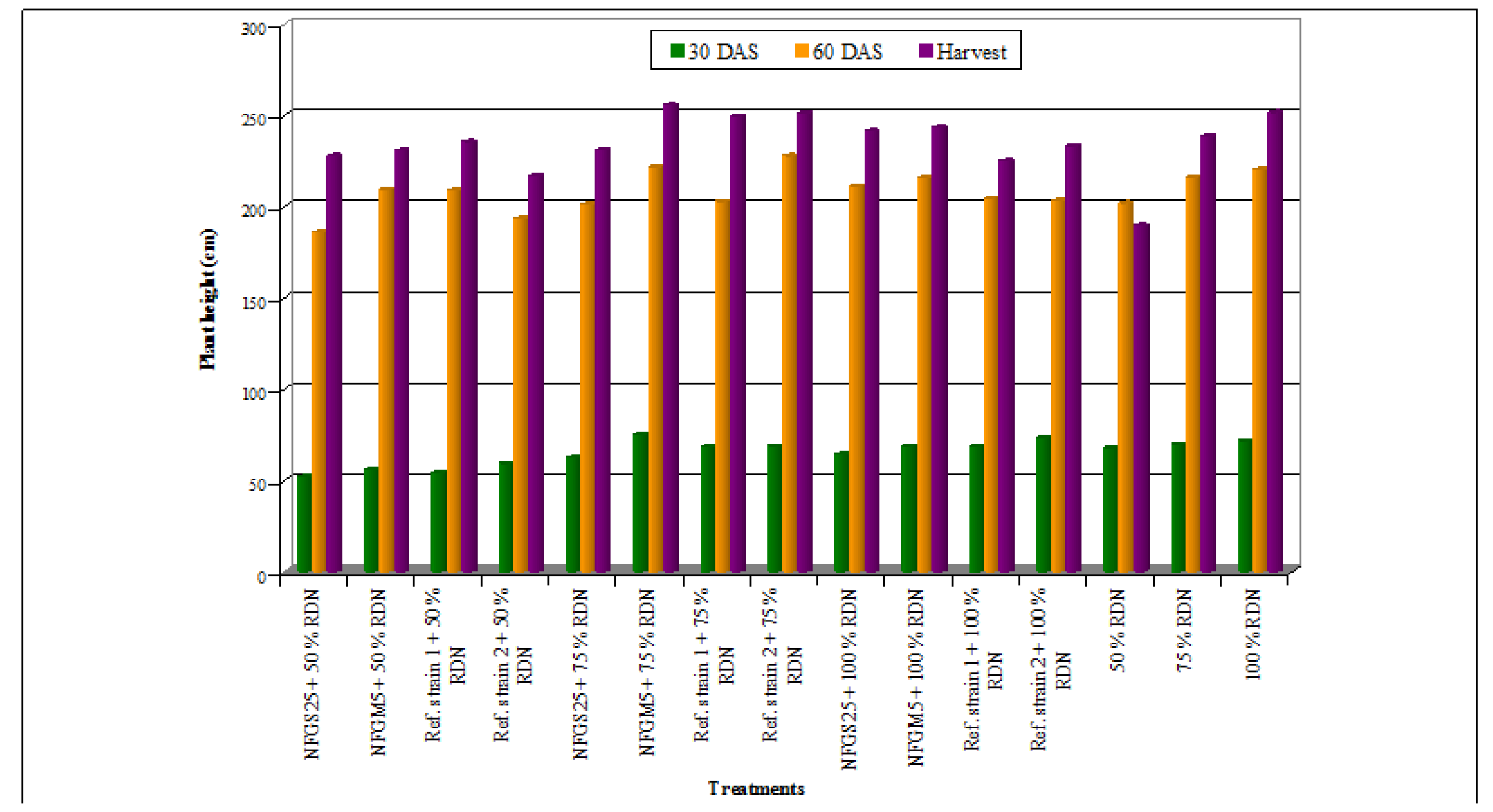


Fig.2 Stem girth of maize as influenced by inoculation of with efficient native isolates of Gluconacetobacter sp. at various nitrogen levels nitrogen levels in the field experiment

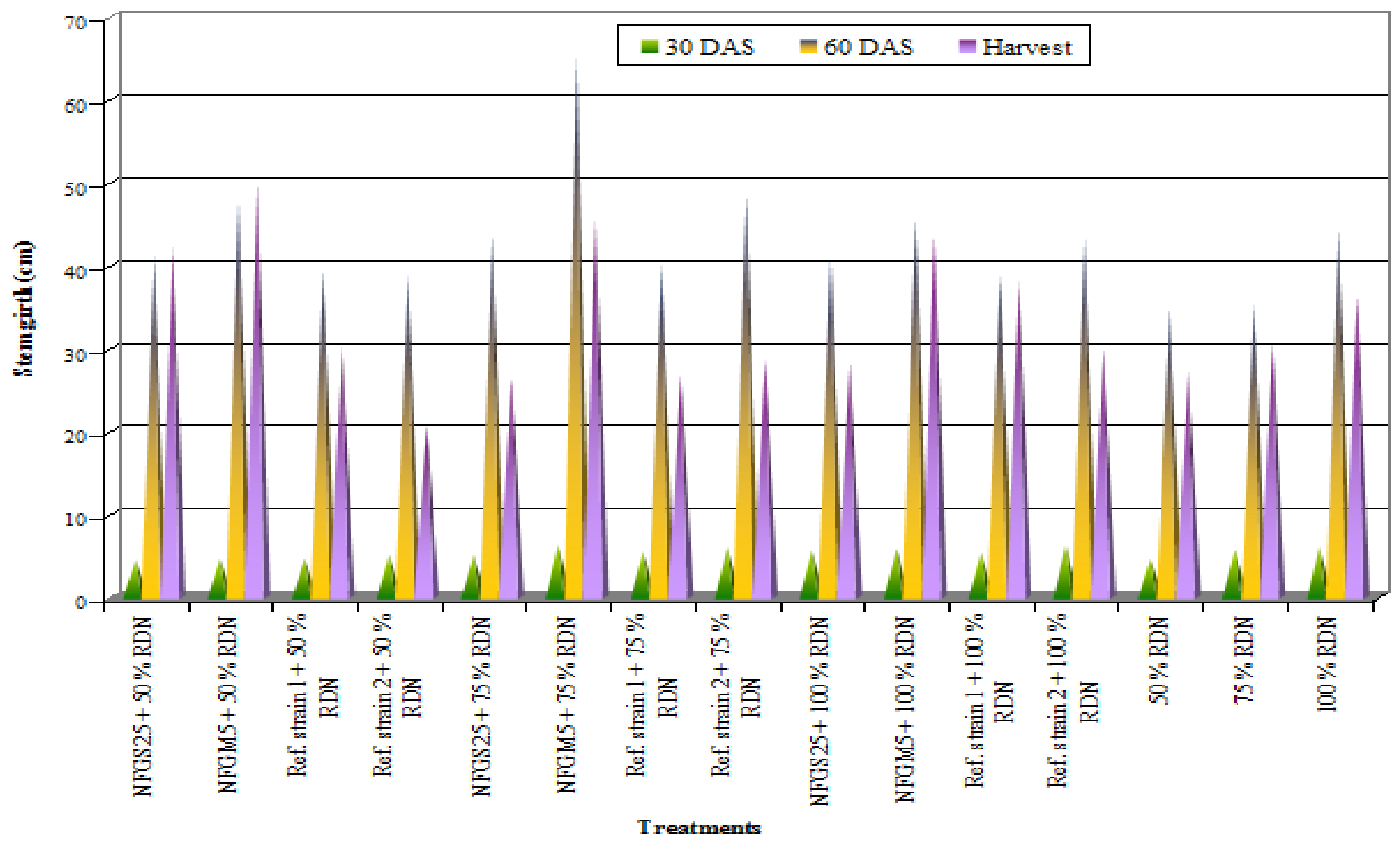


Fig.3 Leaf chlorophyll content (SP AD) of maize as influenced by efficient native isolates of Gluconacetobacter sp. at various nitrogen levels nitrogen levels in the field experiment

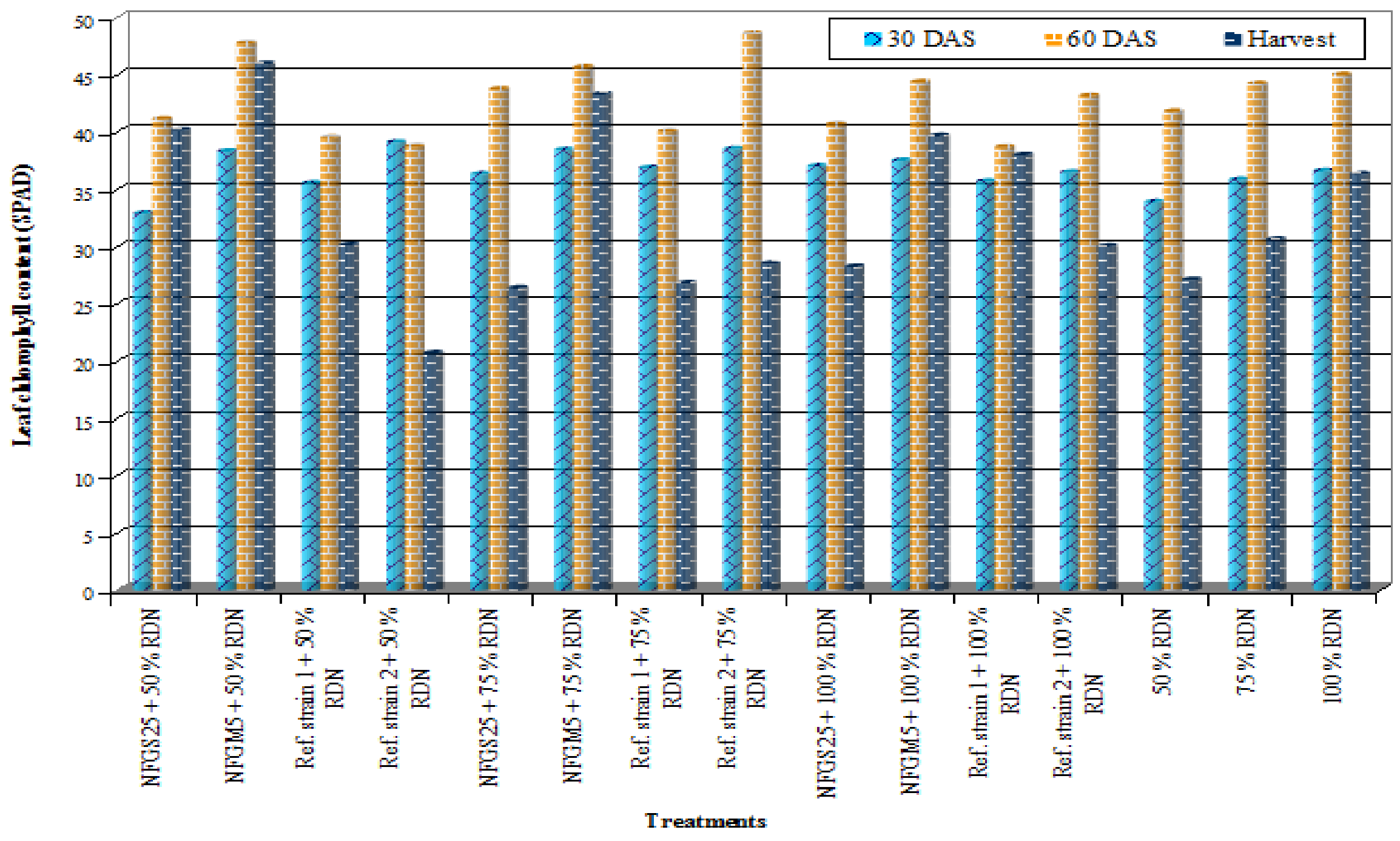


Fig.4 Dry weight of shoot of maize as influenced by efficient native isolates of Gluconacetobacter sp. at various nitrogen levels nitrogen levels in the field experiment

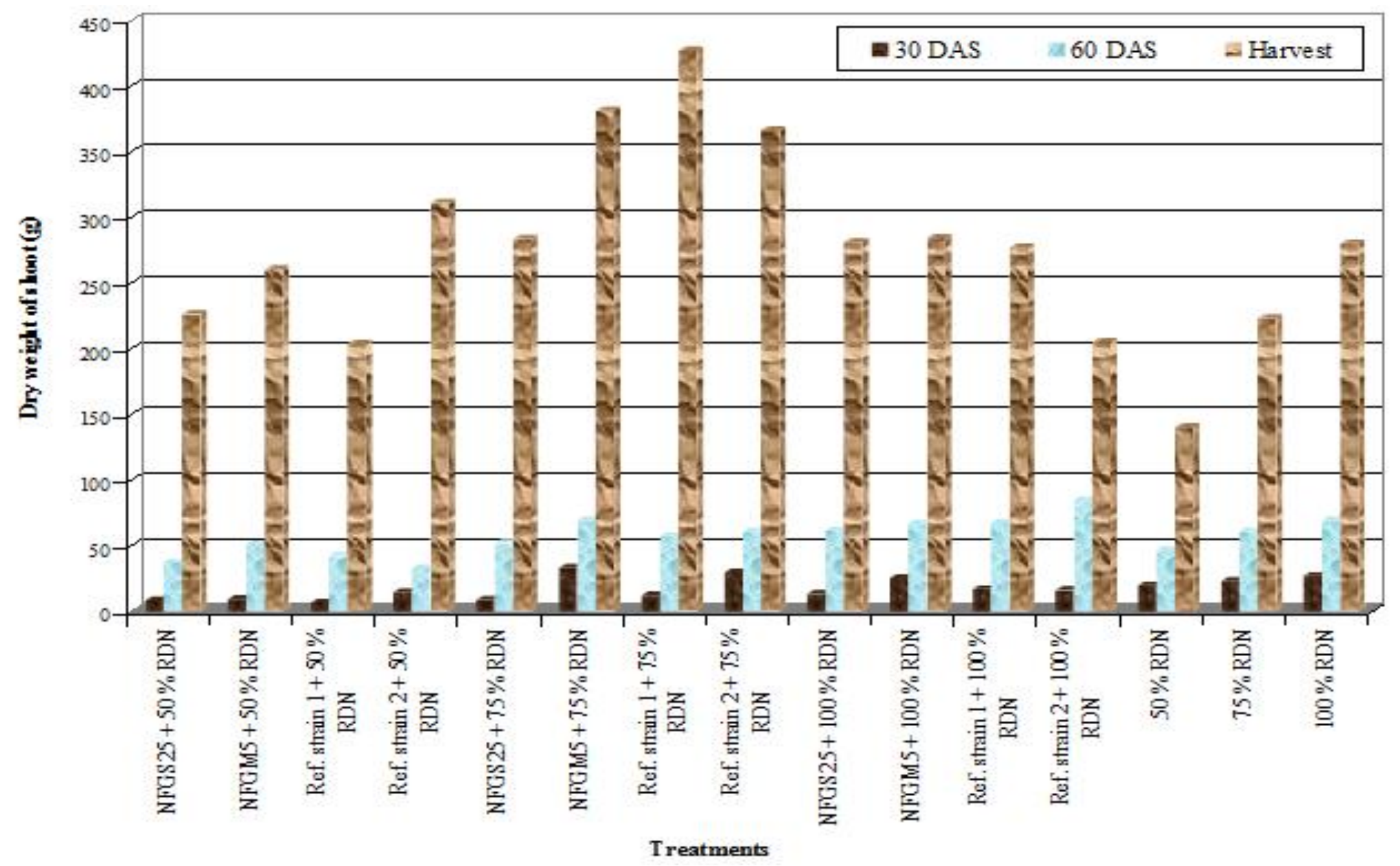


Fig.5 Dry weight of root of maize as influenced by efficient native isolates of Gluconacetobacter sp. at various nitrogen levels in the field experiment

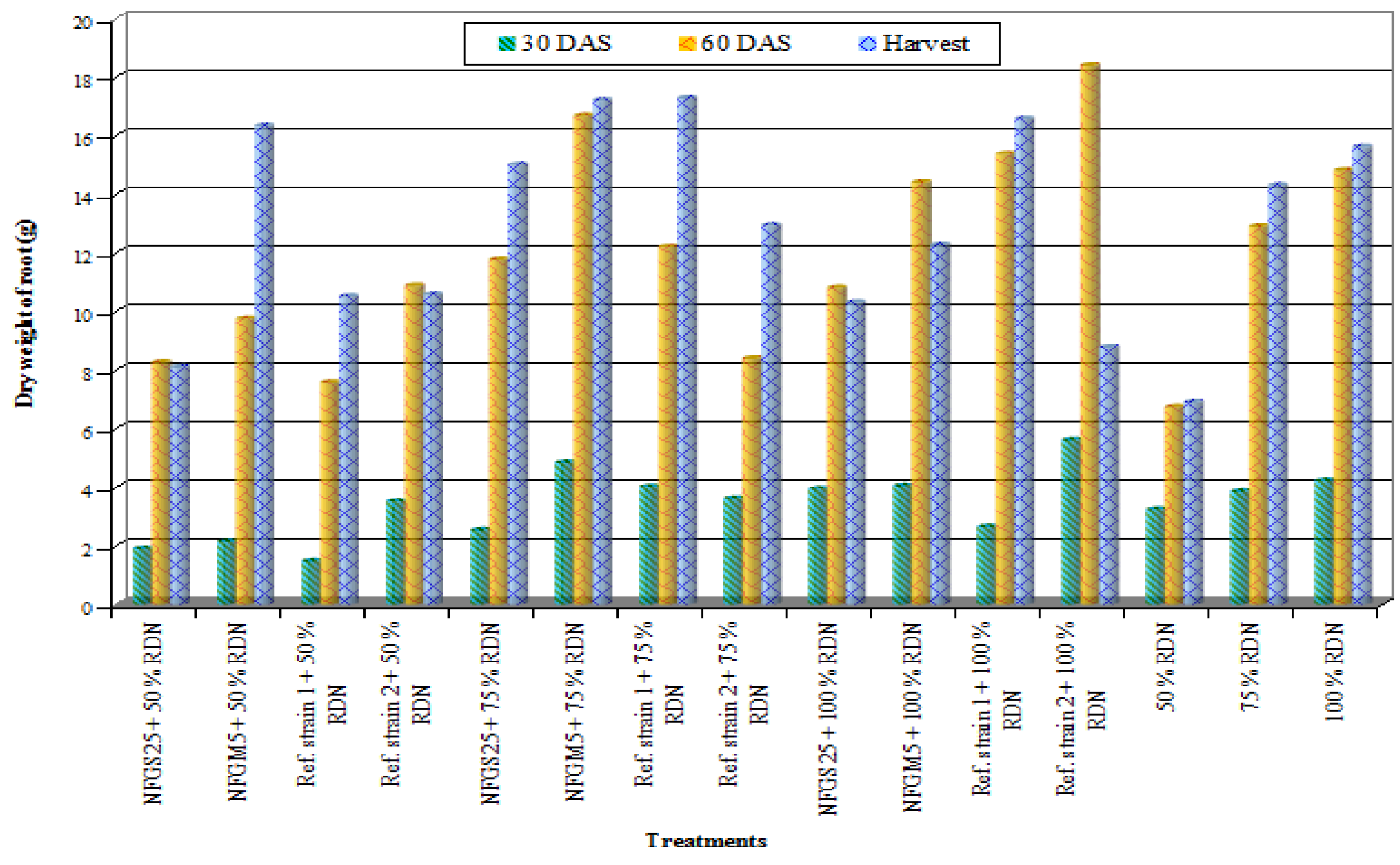


Fig.6 Nitrogen concentration of shoot of maize as influenced by inoculation with efficient native isolates of Gluconacetobacter sp. at various nitrogen levels in the field experiment

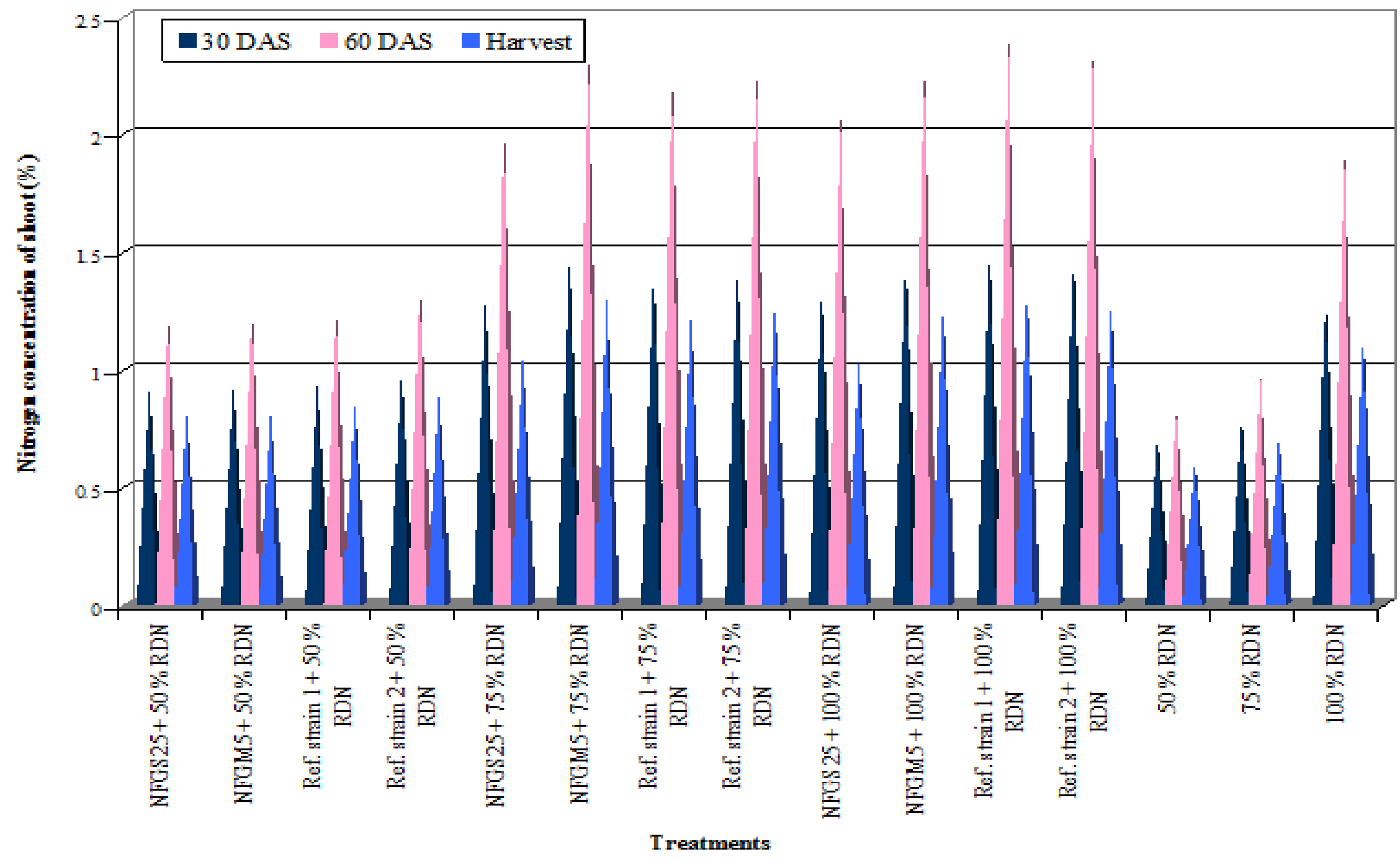


Fig.7 Nitrogen concentration of root of maize influenced by efficient native isolates of Gluconacetobacter sp. at various nitrogen levels nitrogen levels in the field experiment

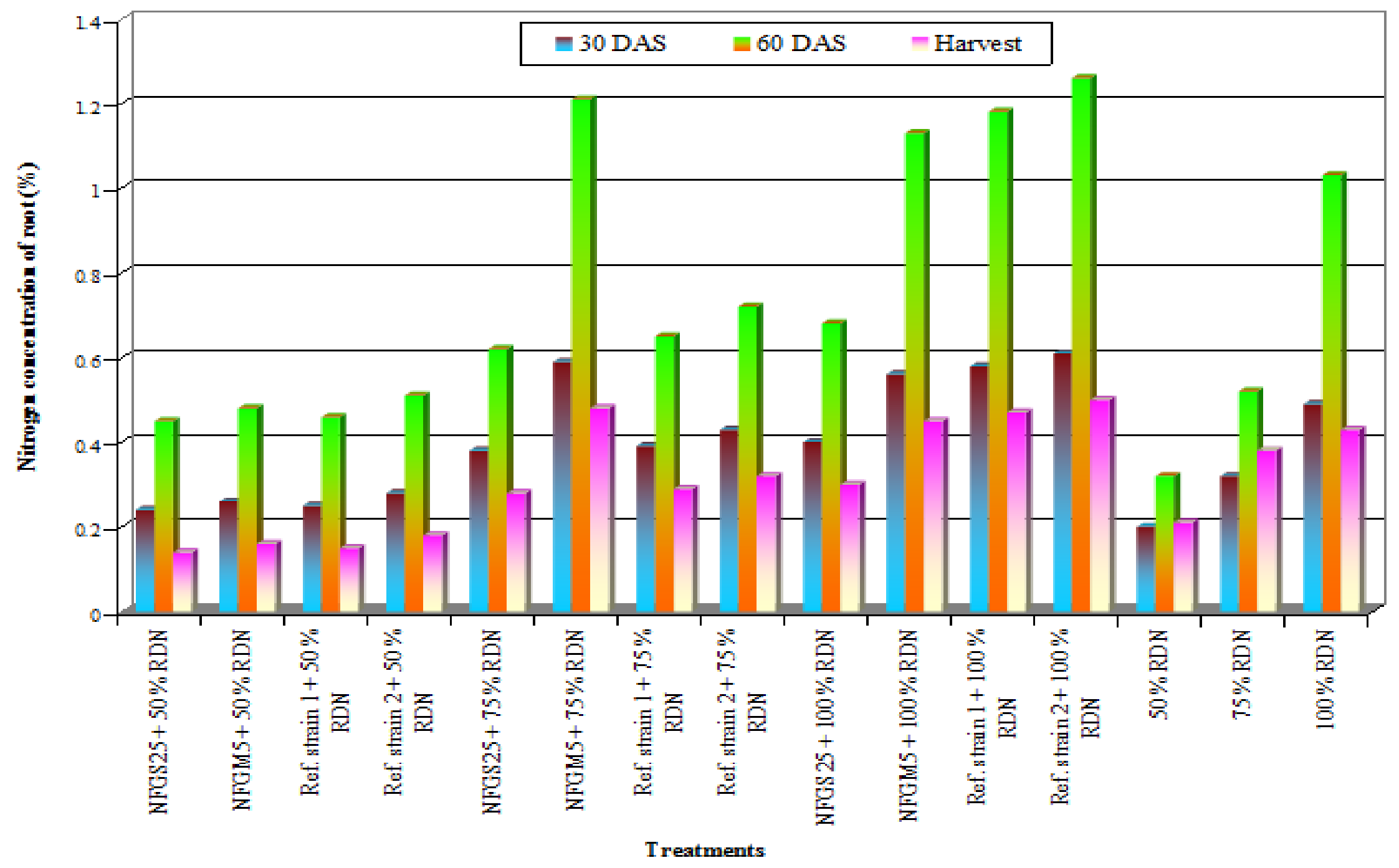


Fig.8 Influence of efficient native isolates of Gluconacetobacter sp. on population dynamics of Gluconacetobacter diazotrophicus at various nitrogen levels in the field trial

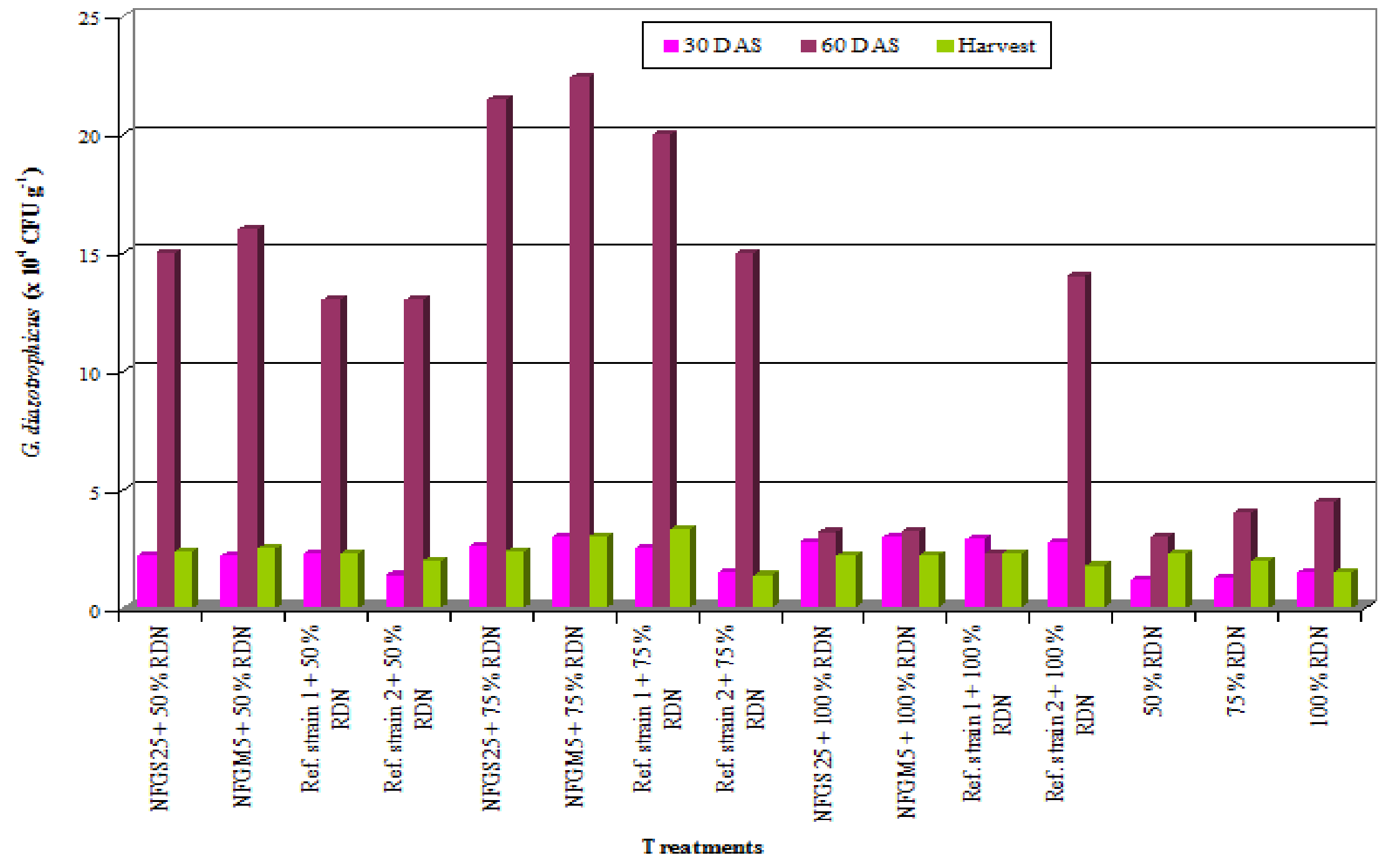


Fig.9 Number of cobs per plant of maize as influenced by efficient native isolates of Gluconacetobacter sp. at various nitrogen levels in the field experiment

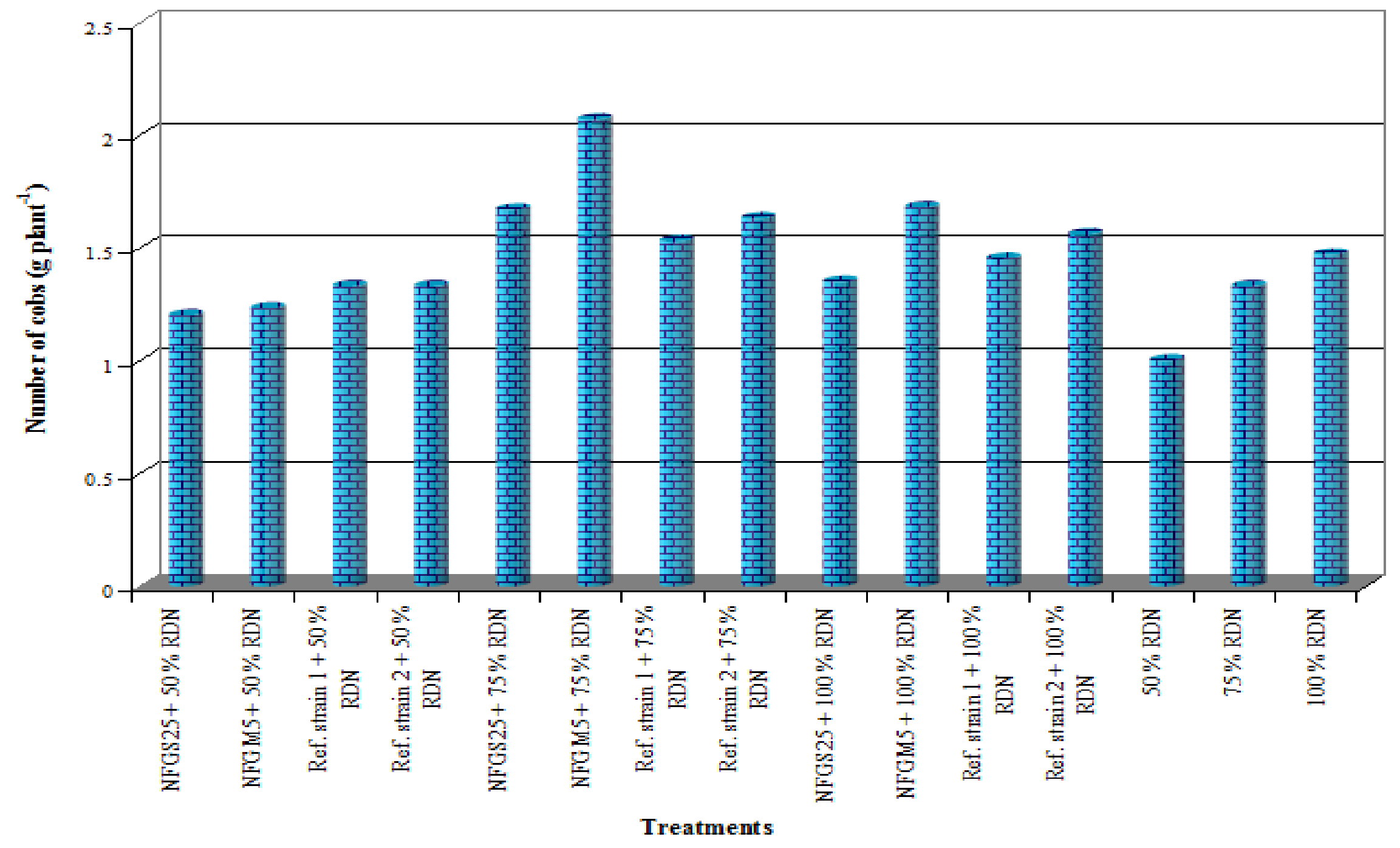


Fig.10 Cobs weight per plant, grain yield per plant and grain yield of maize influenced by efficient native isolates of Gluconacetobacter sp. at various nitrogen levels in the field experiment

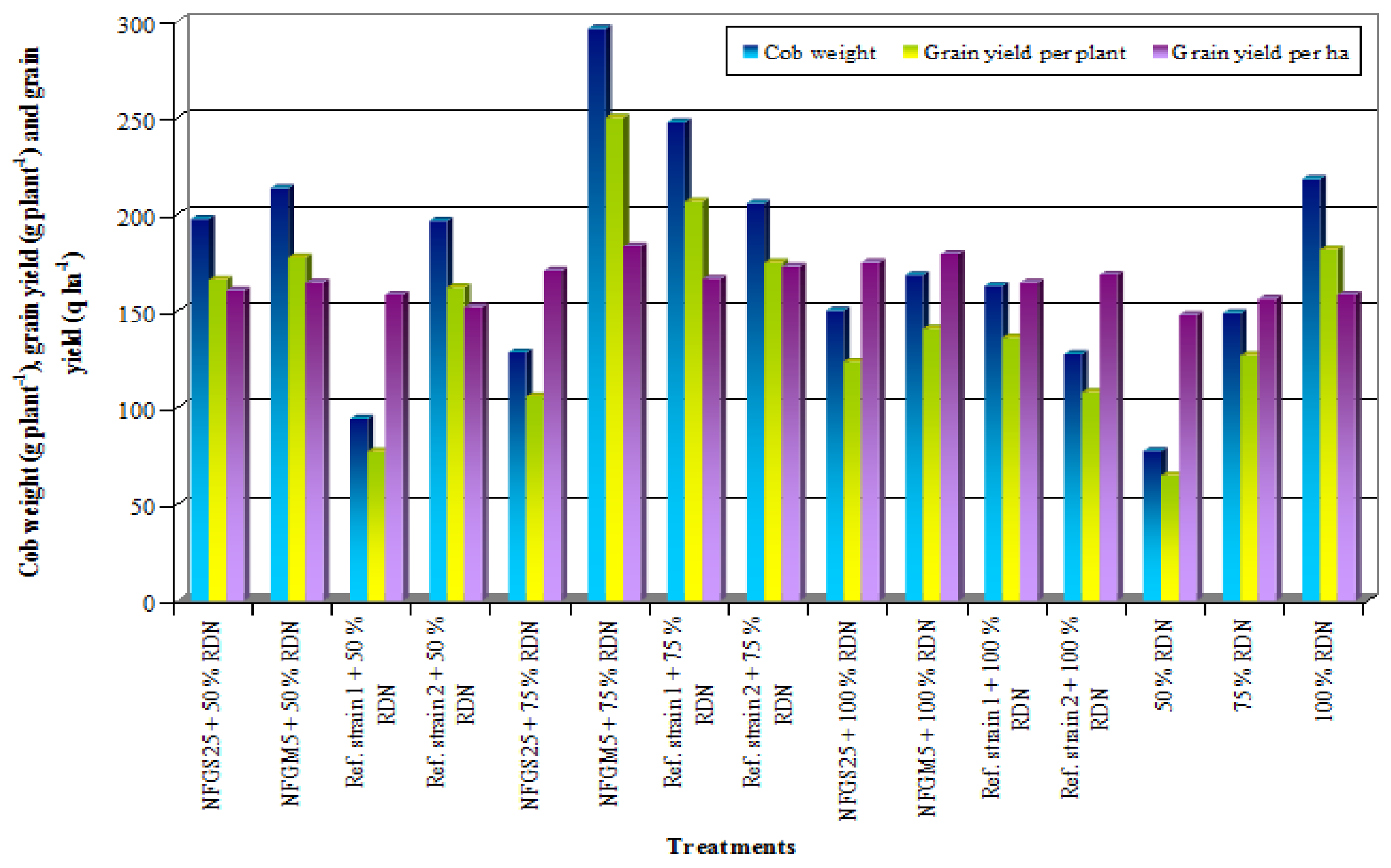


Fig.11 Test weight of maize influenced by efficient native isolates of Gluconacetobacter sp. at various nitrogen levels in the field experiment

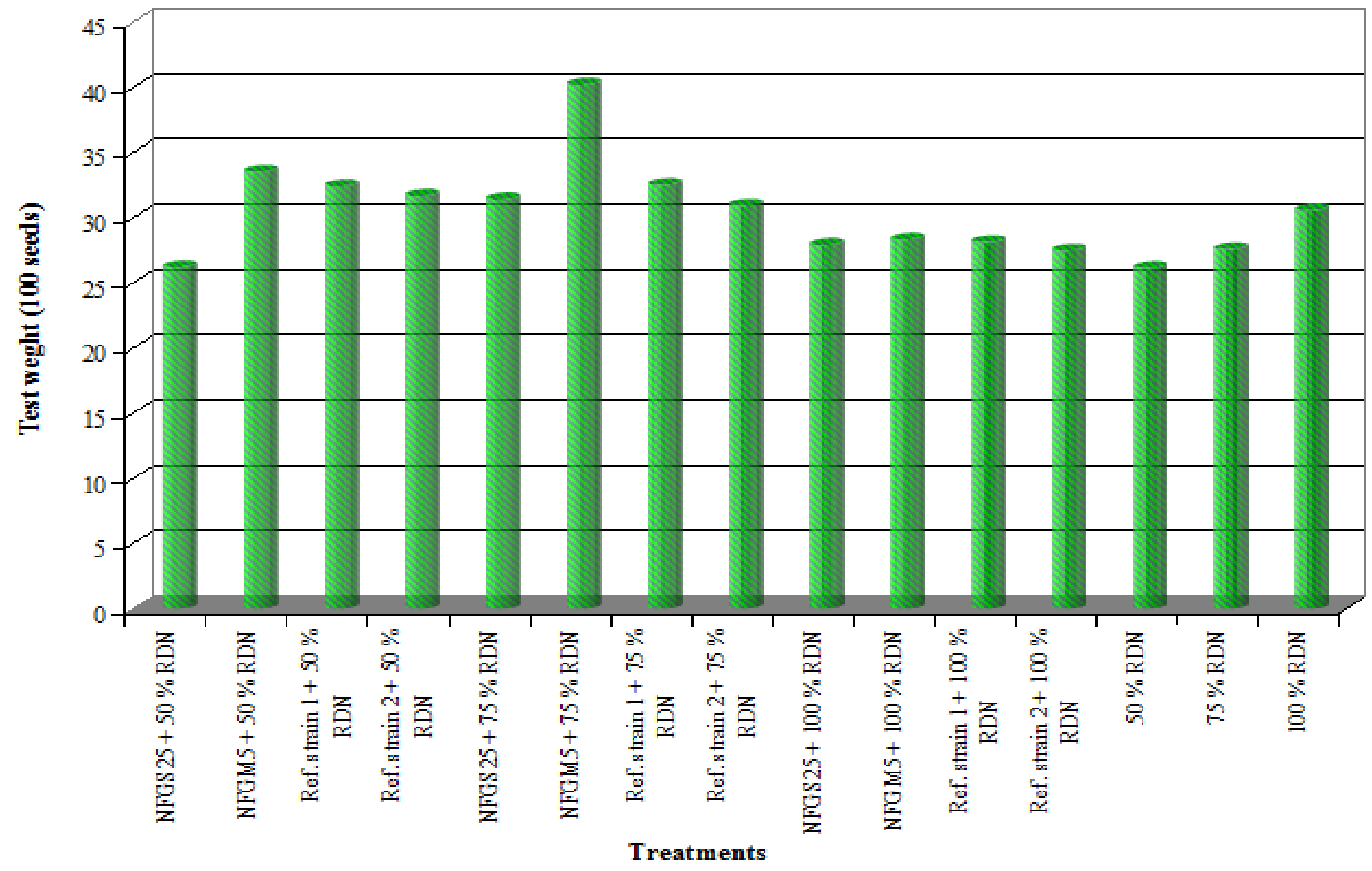


Int.J.Curr.Microbiol.App.Sci (2019) 8(1): 1497-1516

Plate.1 General view of the field experiment

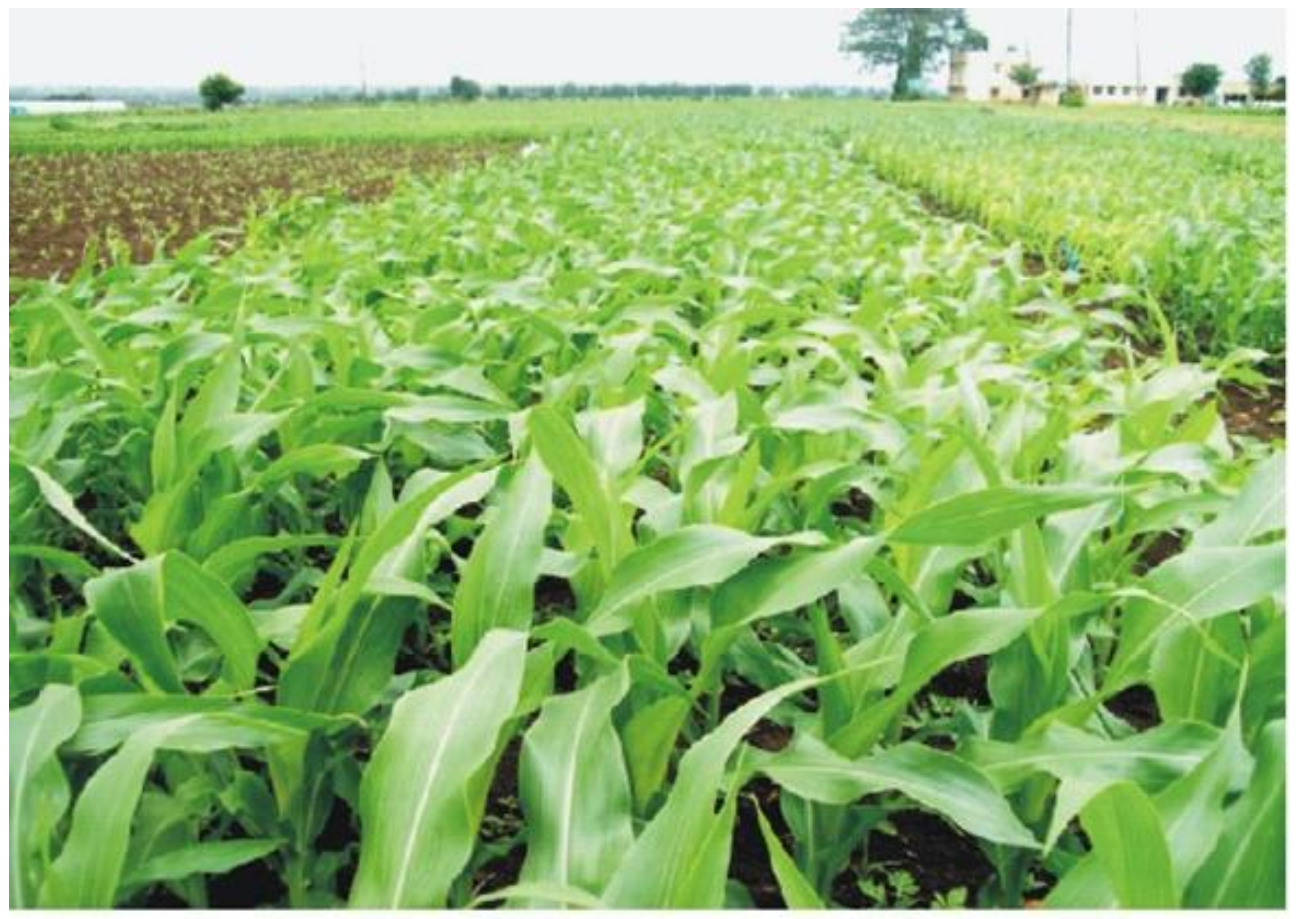

a) 30 days after sowing

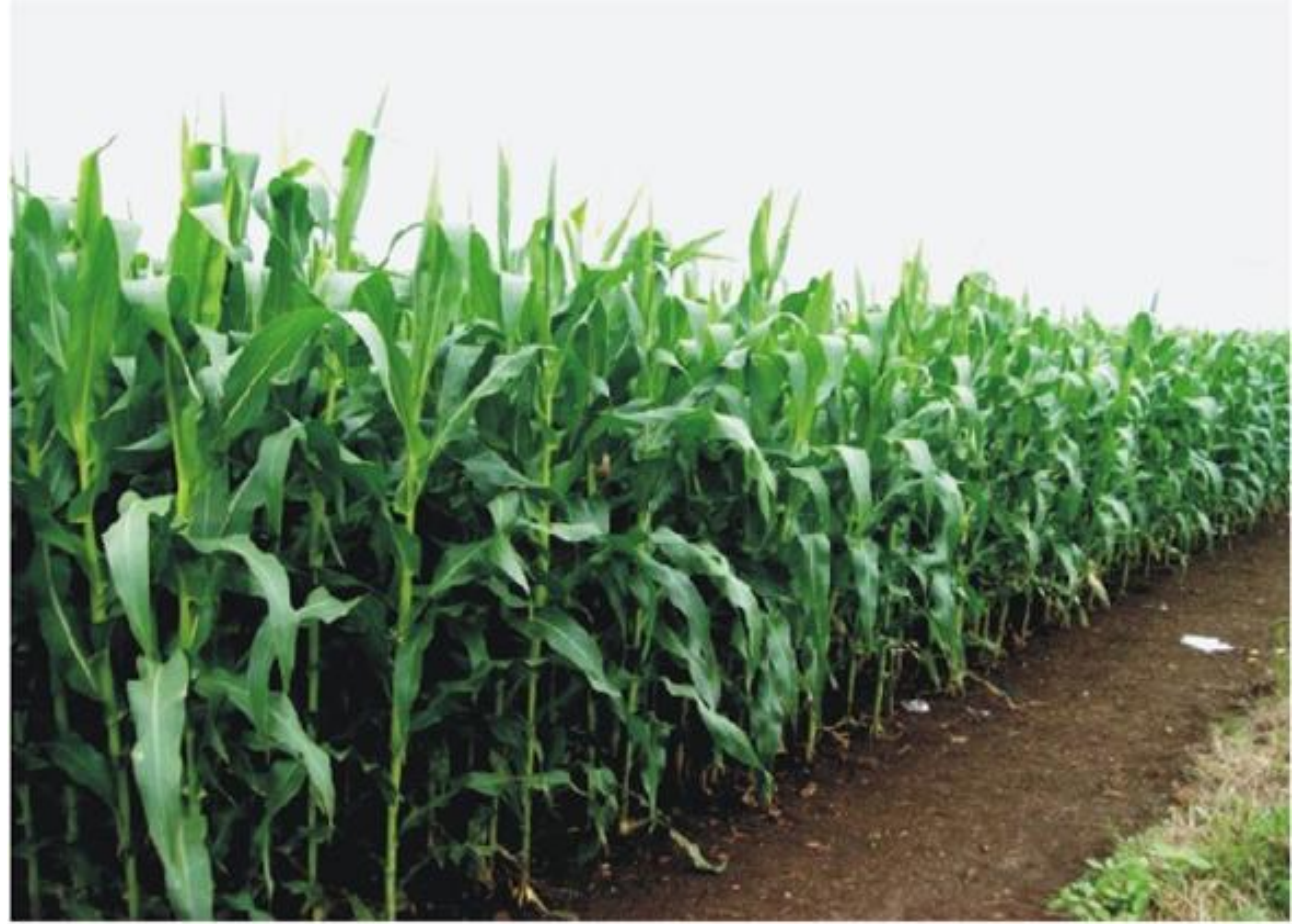

b) 90 days after sowing 
Plate.2 Effect of inoculation of efficient native isolates of Gluconacetobacter sp. on maize under graded levels of nitrogen

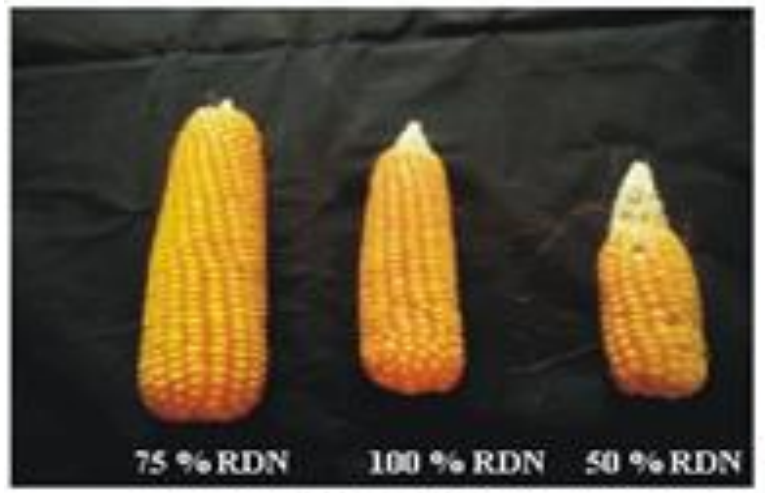

b) NFGS25

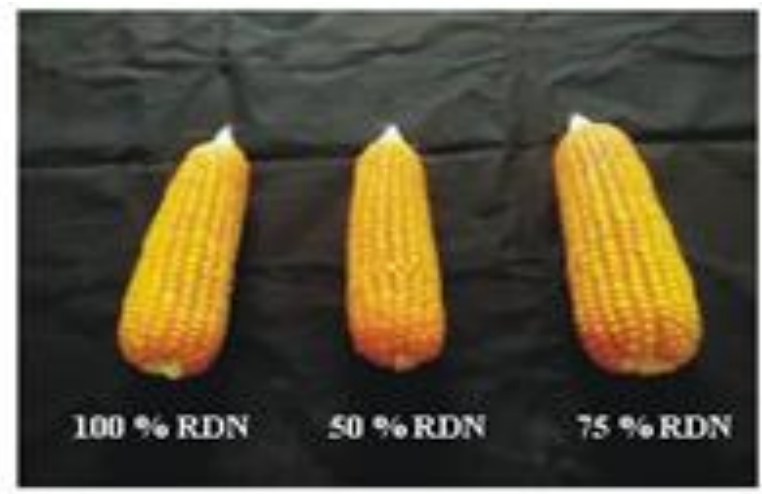

a) NFGMS

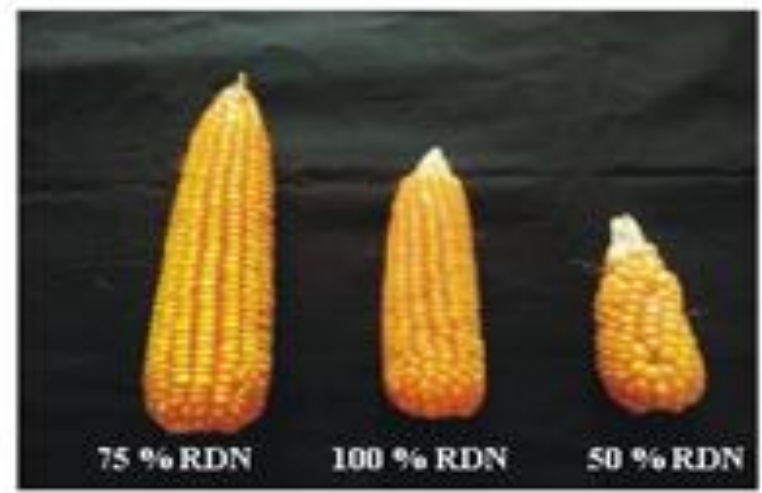

C) Asosspirillum ACD15

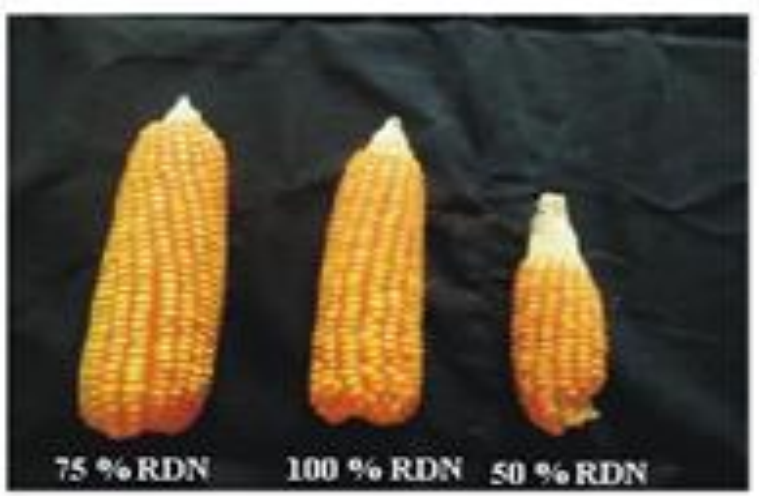

d) G diazotrophiaus MTCC1224 
Plate.3 Genomic DNA from bacterial sample using the bacterial genomic DNA isolation Kit

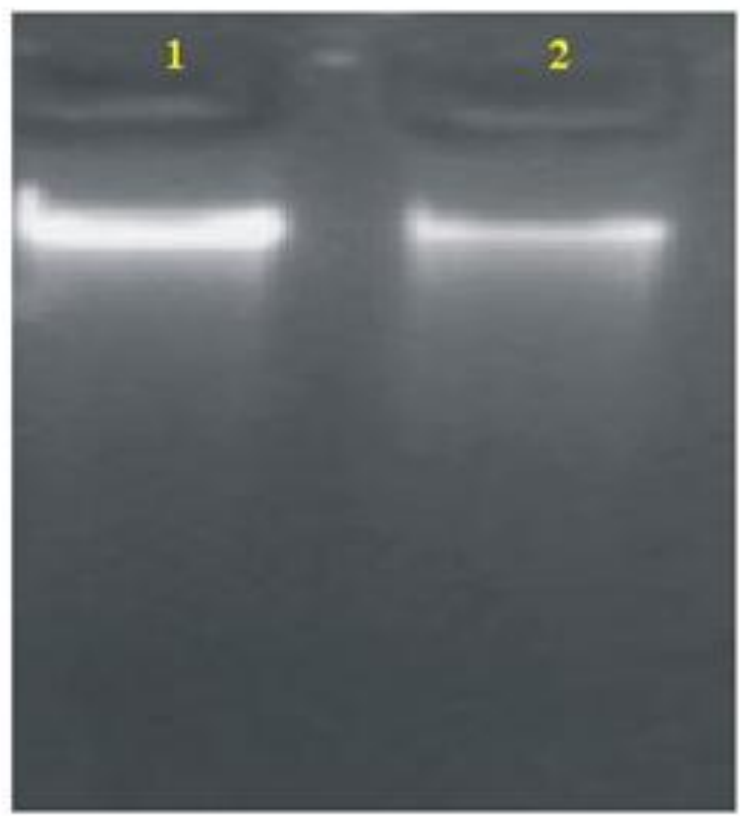

Plate.4 PCR amplification of 16s rDNA fragment from bacterial sample loaded on $1 \%$ agarose gel

\section{Lane description:}

1. Genomic DNA from sample 1 (NFGS25)

2. Genomic DNA from sample 2 (NFGMS)

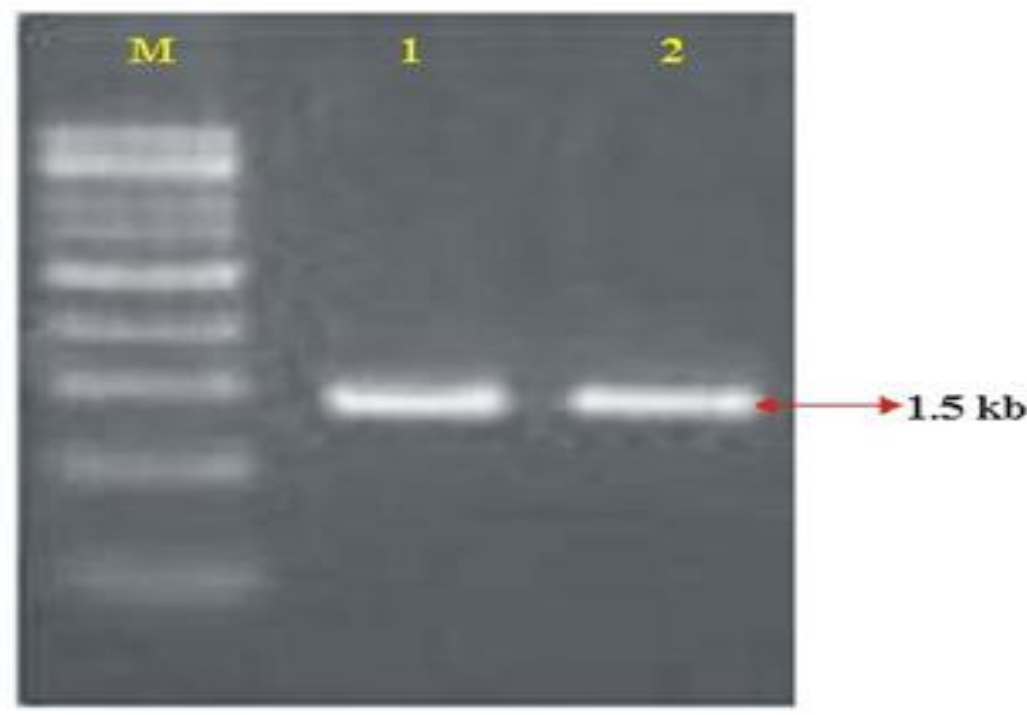

This was true even under in vitro condition. The results of nitrogen fixation estimation indicated that the nitrogenase activity was not hindered in the presence or absence of nitrogen source in the medium. This property is not found in other nitrogen fixer, Azospirllum. Hence activity of Azospirillum reduced at $100 \% \mathrm{RDN}$ level. However, at 75 $\%$ RDN level, they performed better. 


\section{Molecular characterization}

For the taxonomic identification, 16s rDNA amplification was done for two efficient isolates. The results indicate that two isolates (NFGS25 and NFGM5) amplified 16s rDNA fragment with 1500 bp size, based on sequencing they are identified as Gluconacetobacter diazotrophicus with $99 \%$ similarity. The results of the study were confirmed by earlier reports (Eskin et al., 2014; Muthukumarasamy et al., 2005; Saravanan et al., 2008 and Tian et al., 2009) $8,17,23,25$ who characterized Gluconacetobacter diazotrophicus at molecular level. Finally, the present study identified native isolates as Gluconacetobacter diazotrophicus at molecular level (Plate No. 3 and 4).

In conclusion, it is an evident that, Gluconacetobacter diazotrophicus isolates inoculated with graded level of recommended dose of nitrogen promotes plant growth and grain yield under field condition. It is possible to save nitrogenous fertilizer up to $25 \%$ of recommended dose, in addition to increase in yield in the field experiment. Therefore, it is possible to mention that Gluconacetobacter diazotrophicus isolates NFGM5 could be used as potential PGPR (Plant Growth Promoting Rhizobacteria) for improving the growth and yield of maize.

\section{References}

Anitha, K. G. and Thangaraju, M., 2010, Influence of $\mathrm{N}$ fertilization on colonization and activity of Gluconacetobacter diazotrophicus in sugarcane. J. Agron. Crop. Sci., 1 (1): 6-11.

Baldani, J. I. and Baldani, V. L. D., 2005, History on the biological nitrogen fixation research in graminaceous plants: special emphasis on the
Brazilian experience. Ann. Brazilian Acad. Sci., 77 (3): 549-579.

Bastian, F., Cohen, A., Piccoli, P., Luna, V., Baraldi, R. and Bottini, R., 1998, Production of indole-3-acetic acid and gibberellins $\mathrm{A} 1$ and $\mathrm{A} 3$ by Acetobacter diazotrophicus and Herbaspirillum seropedicae in chemically-defined culture media. Plant Growth Regulation, 24(1): 7-11.

Cavalcante, V. A. and Dobereiner, J., 1988, A new acid-tolerant nitrogen fixing bacterium associated with sugarcane. Plant Soil, 108: 23-31.

Cocking, E. C., Philip J. S. and Michael R. D., 2006, Intracellular colonization of roots of arabidopsis and crop plants by Gluconacetobacter diazotrophicus. In Vitro Cell. Dev. Biol. Plant, 42: 74-82.

Dobereiner, J., 1992, History and new perspectives of diazotrophs in association with non-leguminous plants. Symbiosis, 13: 1-13.

Dong, Z., Heydrich, M., Bernard, K. and McCully, M. E., 1995, Further evidence that the $\mathrm{N}_{2}$ fixing endophytic bacterium from the intercellular spaces of sugarcane stems is Acetobacter diazotrophicus. Appl. Environ. Microbiol., 61: 1843-1846.

Eskin, N., Vessey, K. and Tian, L., 2014, Research progress and perspectives of nitrogen fixing bacterium, Gluconacetobacter diazotrophicus in monocot plants. Int. J. Agronomy, 2: 113.

Hernandez, A.T., Bustillos-Cristales, M.R., Jimenez-Salgado, T., CaballeroMellado, J. and Fuentez-Ramirez, L.E. 2000. Natural endophytic occurrence of Acetobacter diazotrophicus in pineapple plants. Microb. Ecol., 39: 49-55.

Jackson, M. L., 1973, Soil Chemical Analysis, Prentice Hall of India Pvt. Ltd., New Delhi, p. 498.

Jiminez - Salgado T., Fuentes - Ramirez 
L.E., Hernandez A.T., Masarua M.A., Martinez - Romero E. and Caballero Mellado J., Coffea arabica L., 1997, A new host plant for Acetobacter diazotrophicus and isolation of other nitrogen fixing acetobacteria, Appl. Environ. Microbiol., 63, 3676-3683

Kersters, K., Lisidiyant, I. P., Komagata, K. and Swings, J., 2006, The family Acetobacteriaceae: The genera Acetobacter, Acidomonas, Asaia, Gluconacetobacter, Gluconobacter and Kozakia. Prokaryotes, 5: 163-200.

Loganathan,P. and Nair, S., 2003, Cropspecific endophytic colonization by a novel, salt-tolerant, Nitrogen fixing and phosphate-

solubilizing Gluconacetobacter sp. from wild rice. Biotechnol. Lett., 25:.497501.

Loganathan P., Sunitha R., Parida A.K. and Nair S., 1999, Isolation and characterization of two genetically distant groups of Acetobacter diazotrophicus from a new host Eleusine coracana L., Journal of Applied Microbiology, 87, 167-172

Luna, M. F., Aprea, J., Crespo, J. M. and
Boiardi, J. L., 2012, Colonization and yield promotion of tomato by Gluconacetobacter diazotrophicus. Appl. Soil Ecol., 61: 225-229.

Muthukumarasamy R., Cleenwerckb I., Revathia G., Vadivelua M., Janssensb D., Hosteb B., Ui Gumc K., Ki-Do Parkc, Sonc C.Y., Sad T. and Melladoe J.C.,2005, Natural association of Gluconacetobacter diazotrophicus and diazotrophic Acetobacter peroxydans with wetland rice, System. Appl. Microbiol., 28, 277-286

Saravanan V.S., Madhaiyan M., Osborne J., Thangaraju M. and Sa T.M., 2008, Ecological occurrence of Gluconacetobacter diazotrophicus and nitrogen-fixing Acetobacteraceae members: their possible role in plant growth promotion, Microb. Ecol., 55, 130-140

Tian, G., Pauls, P., Dong, Z., Reid, L. M. and Tian, L., 2009, Colonization of the nitrogen-fixing bacterium Gluconacetobacter diazotrophicus in a large number of Canadian corn plants. Can. J. Plant Sci., 89: 1009-1016.

\section{How to cite this article:}

Hema C. Rao and Savalgi, V.P. 2019. Field Evaluation of Nitrogen Fixing Endophytic Bacterium Gluconacetobacter diazotrophicus NFGM5 on Growth and Yield of Maize. Int.J.Curr.Microbiol.App.Sci. 8(01): 1497-1516. doi: https://doi.org/10.20546/ijcmas.2019.801.160 